\title{
O HUMILDE PATRIMÔNIO DE MANUEL BANDEIRA
}

\author{
André Luís Mourão de Uzêda \\ Doutorando em Ciência da Literatura (Teoria Literária) pela UFRJ \\ andreuzeda@ufrj.br
}

\section{RESUMO}

Apresentamos os resultados preliminares de nossa pesquisa de doutorado pela leitura do volume Crônicas da província do Brasil, de Manuel Bandeira, com o intuito de nele revelar um modo de concepção patrimonial que se manifesta tanto em forma quanto em tema. Com relação à forma, tomamos o dado de "humilde cotidiano" como chave de leitura para conceber poeticamente uma "visão de mundo patrimonial". Como tema, analisamos três aspectos que atravessam o tratamento dado ao patrimônio na obra: material, imaterial e literário.

Palavras-chave: Crônicas da província do Brasil, Humildade, Manuel Bandeira, Patrimônio cultural e literário.

\begin{abstract}
We present preliminary results of our doctoral research by reading Manuel Bandeira's Crônicas da província do Brasil, with the aim of revealing a patrimonial mode conception that manifests itself both in form and in theme. Regarding to form, we elect the "humble day-to-day" as a starting point for poetically conceiving a "patrimonial worldview". As theme, we have analyzed three aspects associated with the given treatment to the matter of heritage in Bandeira's work: tangible, intangible and literary.
\end{abstract}

Keywords: Crônicas da província do Brasil, Humility, Manuel Bandeira, Cultural and literary heritage.

\section{INTRODUÇÃO}

Já é de grande reconhecimento a contribuição dos intelectuais modernistas na consolidação de um projeto de resgate, valorização e construção do patrimônio cultural nacional. Marcado pela paradoxal peculiaridade de ser justamente um movimento de vanguarda o responsável pela valorização das manifestações artísticas da tradição, especialmente no interesse pelo Barroco brasileiro, nosso Modernismo encontra no passado 
a originalidade inspiradora que determinará seu tempo de produção no presente e a preservará para o futuro das gerações brasileiras.

Mário de Andrade é figura central nesse debate. Autor do anteprojeto do Serviço do Patrimônio Histórico e Artístico Nacional (SPHAN), Mário deu início a várias ações no campo da preservação e difusão dos bens culturais consideradas ainda hoje arrojadas para as discussões em torno da ideia de patrimônio. Ao redor de Mário de Andrade, uma constelação de artistas e intelectuais na primeira metade do século XX contribui para delinear a trajetória histórica na empreitada pela constituição do projeto político-cultural modernista de salvaguarda do patrimônio cultural brasileiro. Basta citar os nomes de Lúcio Costa, Oscar Niemeyer, Rodrigo Melo Franco de Andrade, Blaise Cendrars, Tarsila do Amaral, Gustavo Capanema, Gilberto Freyre, Sérgio Buarque de Holanda, entre tantos outros agentes em defesa da "causa patrimonial", os quais foram fundamentais para que outro projeto político para o patrimônio, encabeçado por Gustavo Barroso, de caráter patriótico, positivista e nacional-estadista, não viesse a ter êxito nas disputas em jogo para as políticas de educação e cultura durante o Estado Novo.

Outro importante intelectual nesse debate merece destaque por sua ação patrimonial, de política tímida e cautelosa, "humilde", como lhe é peculiar, que nossa pesquisa de doutorado em andamento objetiva enfatizar: o poeta e cronista Manuel Bandeira. Diferentemente de Mário de Andrade (com quem manteve vasta e intensa correspondência), Bandeira não teve seu nome gravado na história pela sua ação "política", no seu sentido mais vulgar (enquanto participação na política institucional e burocrática). Mas exerceu, com maestria, uma política em seu sentido mais originário, como partícipe da 
vida pública, do debate público, da pauta do dia que versa sobre os mais variados temas de interesse social. Tal atuação se dá, principalmente, na imprensa brasileira e, por isso, a presente pesquisa tem como foco a produção de crônicas do autor veiculadas nos mais variados periódicos brasileiros. No presente estudo, restringimo-nos às crônicas do volume Crônicas da província do Brasil, publicado em 1937, que apresenta, na multiplicidade de assuntos abordados, um fio condutor que as alinha em torno de uma concepção original e poética no tratamento dado ao patrimônio. Denominamos esse tratamento de a visão de mundo patrimonial de Manuel Bandeira.

Para a empreitada prevista para esse trabalho - qual seja: a fundamentação de uma poética que orienta a questão patrimonial nas Crônicas da província do Brasil -, o presente artigo dirige-se no seguinte caminho: iniciamos por breve contextualização histórica das condições de produção em que se dá a publicação do volume. Em seguida, passamos aos postulados teóricos em que nos baseamos para fundamentar uma concepção poética patrimonial em Manuel Bandeira, tomando como chave de leitura a ideia de "humilde cotidiano" de que nos fala o poeta. Ao final, fazemos breve menção a algumas das crônicas em que se nota a presença de sua visão de mundo patrimonial a partir de três eixos de análise: i. a preservação do patrimônio histórico e artístico material; ii. a valorização das manifestações culturais de caráter imaterial; iii. a difusão do patrimônio literário brasileiro de seu tempo de produção.

\section{BREVE PANORAMA PELAS CRÔNICAS DA PROVÍNCIA DO BRASIL}

Composto por 47 crônicas publicadas na imprensa nacional entre 1928 e 1933, selecionadas e organizadas pelo próprio autor, Crônicas da província do Brasil é o primeiro 
livro em prosa de Manuel Bandeira, publicado à época pela renomada editora Civilização Brasileira, em virtude da comemoração de seus cinquenta anos de idade no ano anterior. Trata-se da primeira edição totalmente custeada por editora, sem qualquer recurso do autor, o que demarca a posição de prestígio ocupada por Bandeira à época. Divide-se em duas partes: a primeira, não intitulada, reúne 42 crônicas em que predomina o interesse do poeta pela cultura artística e literária brasileira, aspecto fundamental a ser analisado no presente estudo. A segunda, intitulada "Outras crônicas", reúne cinco textos de assuntos variados que não contemplam a temática nacional. Há na ordenação das Crônicas da província do Brasil uma organicidade interna que prenuncia a fundamentação de uma visão de mundo patrimonial de elaboração do pensamento ético e estético como um fecundo campo a ser explorado tanto em matéria quanto em forma. Detemo-nos, primeiramente, sobre alguns elementos que apontam para uma presença patrimonial na disposição orgânica do volume.

Partindo do título, chama atenção o fato de não se tratarem de crônicas do Brasil, ou crônicas brasileiras, mas de crônicas "da província" do Brasil. Fazendo da província o núcleo da locução adjetiva e subordinando sintagmaticamente "do Brasil" a ela, Bandeira já nos propõe uma inversão de perspectiva que se confirma pela leitura da sua "Advertência":

A maioria destes artigos de jornal foram escritos às pressas para A Província do Recife, Diário Nacional de São Paulo, e o Estado de Minas de Belo Horizonte. Eram crônicas de um provinciano para a província. Aliás este mesmo Rio de Janeiro de nós todos não guarda, até hoje, uma alma de província? O Brasil todo é ainda província. Deus o conserve assim por muitos anos. (BANDEIRA, 2006, p. 11)

Ainda em investigação em nossa pesquisa, a concepção de Bandeira para "província" é de extrema relevância para esse estudo. Estranha ao leitor que a afirmação "Deus o 
conserve assim por muitos anos" quebre a expectativa naturalmente esperada de ler no termo "província" o tom pejorativo a que usualmente está sujeito. A província, afastada do governo central, periférica à metrópole, derivou-se em sentido como "atraso" ou "subdesenvolvimento", como que à sombra da luz emanada pelo centro. Ao empregar o termo, Bandeira não propõe sua ressignificação; antes, valoriza a província exatamente pelo que tem de pouco sofisticada ou desenvolvida, enaltecendo o que tem de interiorana. A obra poética do autor pode nos trazer algumas chaves de leitura que corroborem nosso argumento. Em "Declaração de amor", de Estrela da manhã, o verso "Tão docemente provinciana" (BANDEIRA, 1993, p. 163), dedicado à cidade mineira de Juiz de Fora, revela a mesma estranheza com a quebra de expectativa em ler positivamente a dimensão da província. Do mesmo modo atua o verso “Diabo leve quem pôs bonita a minha terra!" (BANDEIRA, 1993, p. 201), em referência às transformações desenvolvimentistas de Recife no poema "Minha terra", de Belo belo. De grandes forças imagéticas, ambos os poemas enaltecem a presença positiva do provincianismo em sua memória afetiva.

Há no movimento de valorização do provincianismo pela relação de suas experiências memoriais afetivas a revelação de um alumbramento poético-patrimonial: ele resguarda o originário, o autêntico, o essencial, o primevo, e por isso precisa ser preservado. À província, o poeta agrega um senso patrimonial que não valoriza o dado monumental, mas que eleva o simplório à categoria de patrimonializável justamente pelo que carrega de menor - porém sublime.

Detemo-nos também sobre a categoria "crônica". Apesar de referir-se na "Advertência" a "artigos de jornal", o poeta intitula o volume como "Crônicas" da província 
do Brasil. Há de fato uma multiplicidade na forma dos textos que diverge muito quando comparados entre si, de modo que o hibridismo tão peculiar ao gênero se faz notoriamente manifesto no conjunto da obra. No exercício da crônica diária, considerando-se as restritas condições de produção de textos efêmeros, fluidos e datados, Bandeira fez do gênero um campo de experimentação literária, nos termos colocados por Davi Arrigucci Jr. (1986). Múltipla e multifacetada, a crônica apropria-se de variadas máscaras na forma como se apresenta. Basta citar, a título de exemplo, os dois textos de abertura das Crônicas da província do Brasil, "De Vila Rica de Albuquerque a Ouro Preto dos estudantes" e "Bahia", que resgatam o sentido da crônica histórica e de viajantes, cuja densidade de páginas contrasta com a leveza pela qual os leitores são conduzidos ao longo da leitura prazerosa. Já as crônicas sobre os escritores modernistas, mais para o final do volume, assumem aspecto de resenha, enquanto as crônicas sobre arte e arquitetura barrocas são impregnadas pelo tom de comentário.

Antecedendo a "Advertência", a dedicatória logo na abertura do volume nos dimensiona o contexto histórico em que se insere a publicação das Crônicas. Bandeira dedica o livro ao amigo Rodrigo Melo Franco de Andrade, autor do projeto de decreto-lei no 25 de 1937, fundador do Serviço do Patrimônio Histórico e Artístico Nacional e seu diretor de 1938 a 1967. Foi ele o responsável por mediar o convite do ministro Capanema para que Bandeira compusesse o Conselho Consultivo do SPHAN, do qual fez parte de 1938 a 1968. Evidentemente, Rodrigo é peça-chave na trajetória da política de proteção do patrimônio cultural brasileiro: seu modo de operar na política estadonovista garantiu a implementação do projeto modernista e de vanguarda que em muito destoava das práticas autoritárias e conservadoras exercidas durante a ditadura varguista. A dedicatória, portanto, prenuncia 
desde já a imbricada relação entre o debate patrimonial em curso na política nacional e as suas registradas impressões nas crônicas do volume.

Com relação ao panorama histórico brasileiro em que se inserem as Crônicas para o debate da nacionalidade no país, Júlio Castañon Guimarães (2006) lembra que a publicação de Crônicas da província do Brasil situa-se na mesma década em que foram lançadas obras fundamentais para a "interpretação do Brasil", como Casa grande \& senzala, de Gilberto Freyre, e Raízes do Brasil, de Sérgio Buarque de Holanda, publicados respectivamente em 1933 e 1936. Crônicas da província do Brasil, evidentemente, não consiste em estudo sistemático, como os ensaios de Freyre e Holanda; contudo, não podemos perder de vista o fato de que suas Crônicas estão inseridas no âmbito de uma preocupação comum, qual seja: a leitura de um Brasil que se delineia na modernidade à luz de nosso passado colonial de economia agrícola, extrativista e de base de trabalho escravocrata. Nelas, aponta-se para "um empenho, se não exatamente de interpretação, pelo menos de conhecimento do Brasil" (GUIMARÃES, 2006, p. 249).

Trazer à tona a memória histórica, artística e cultural das bases de fundação desse país é um legado importantíssimo registrado e difundido por Bandeira, em consonância com o projeto estético e político modernista para a preservação do patrimônio cultural brasileiro. Não é por acaso que a presença patrimonial no volume seja tão fortemente observada em tema e forma, como veremos a seguir. É interesse de nossa pesquisa investigar de que modo a seleção e a disposição das crônicas nos trazem ganhos de interpretação na tarefa de evocar a presença de uma concepção patrimonial em sua obra. Nesse sentido, Guimarães nos indica fértil percurso metodológico a ser trilhado: olhar para todo o conjunto de textos 
publicados por Bandeira na imprensa durante o período de colaboração nos periódicos de onde foram originalmente extraídos (de 1928 a 1933), o que permitirá “avaliar melhor, por contraposição, o tipo de seleção feita para o livro. Ou seja, a verificação do que não foi selecionado informa também sobre o intuito da escolha" (GUIMARÃES, 2006, p. 249). Para a continuidade da pesquisa ainda em curso, empenharemos nossos esforços nessa direção.

\section{A HUMILDADE COMO CHAVE DE LEITURA PARA A DIMENSÃO PATRIMONIAL}

Em sua autobiografia poética, Itinerário de Pasárgada, Manuel Bandeira faz-nos a seguinte confissão:

A Rua do Curvelo ensinou-me muitas coisas. Couto foi avisada testemunha disso e sabe que o elemento de humilde quotidiano que começou desde então a se fazer sentir em minha poesia não resultava de nenhuma intenção modernista. Resultou, muito simplesmente, do ambiente do Morro do Curvelo. [...] Lá escrevi quatro livros, três de poesias [...] e um de prosa - as Crônicas da província do Brasil. (BANDEIRA, 2012, p. 82-83)

Propomos, para iniciar a discussão em torno de uma "visão de mundo patrimonial" na obra de Manuel Bandeira, partir do "elemento de humilde quotidiano" mencionado pelo poeta. Para tanto, é fundamental contextualizá-lo. Referindo-se ao escritor Ribeiro Couto, amigo particular de Bandeira, o poeta baliza o período em que viveu na Rua do Curvelo para o amadurecimento de sua obra. De fato, a Rua do Curvelo, metonímia para todo o bairro de Santa Teresa, está vivamente presente em sua poesia a partir de Libertinagem, em que o dado do prosaico, do costumeiro e do cotidiano assume centralidade para a sua poética. Não é sem propósito que a rua seja enaltecida pelo poeta, onde Bandeira amadurece o que aprendera desde cedo com a companhia paterna: “a poesia está em tudo - tanto nos amores como nos chinelos, tanto nas coisas lógicas como nas disparatadas" (BANDEIRA, 
2012, p. 27), como afirma em suas memórias. Pelas janelas quebradas, a experiência de vida com o humilde cotidiano lhe invade casa adentro e se constitui em elemento material de composição poética e de temática para as suas crônicas.

Valendo-se da chave de leitura do humilde cotidiano, estabelecemos diálogo com a crítica de Davi Arrigucci Jr. (2003) para a obra de Bandeira. Para o ensaísta, o humilde cotidiano é "fonte escondida" na poesia do autor. Partindo sua leitura do poema "Maçã" (BANDEIRA, 1993, p. 168), de Lira dos Cinquent'anos, o crítico analisa a revelação do sublime oculto disfarçado em aparente "discurso humilde", ou, em suas palavras, o desvelar de "uma poética, uma concepção do fazer poético, para a qual o sublime se acha no mais oculto cotidiano" (ARRIGUCCI Jr., 2003, p. 44).

O poema, aparentemente de tópico simples, situa e retrata o fruto observado tal como a pintura de uma natureza morta pelo sujeito lírico do poema, que em progressão temática vai do olhar para o objeto (a maçã circunscrita em si mesma), penetra-o até as sementes e alarga-se, em distanciado posicionamento: disposto sobre a mesa, enfurnado em um pobre quarto de hotel. O tema do humilde cotidiano está claramente posto: uma cena prosaica, num momento de vida retida, de mera contemplação pelo poeta, fixada no tempo e no espaço em razão da concretização do poema. Resta ao leitor o "alumbramento" do que é dado sublime: as "pevides", isto é, as sementes do fruto, o que há de menor e aparentemente de pouco valor, revelam o elevado e inapreensível mistério da vida: "É o infinitamente pequeno que constitui a vida, princípio infinitamente grande que na maçã se exprime" (ARRIGUCCI Jr., 2003, p. 42). 
A simbologia arquetípica encarnada pelo tópico da maçã na tradição clássica e judaico-cristã avança-nos na interpretação do poema em busca de desentranhar o alumbramento do poético ocultado no discurso humilde pela evocação de outras maçãs da história da arte e da literatura, em que se sobressai o âmbito do mítico-sagrado:

[...] [A] maçã identificada com o fruto da árvore do conhecimento no Gênesis, arrastando consigo a duplicidade do mal, seria propriamente um produto da tradição, influenciada pela conotação erótica da fruta na mitologia grega pagã e, na Idade Média, pelo trocadilho $m \bar{a} l u m=$ maçã e $m$ ălum = mal [...]. (ARRIGUCCI Jr., 2003, p. 37-38)

A recuperação da tradição clássica e judaico-cristã interessa-nos sobremaneira para pensar o discurso em torno do humilde cotidiano, que nos permite seguir na direção apontada por Arrigucci Jr. ao recuperar o tratamento dado por Erich Auerbach (2012) sobre o sermo humilis nas transformações operadas na linguagem retórica e literária cristã na transição da Antiguidade tardia para a Idade Média. De acordo com o filólogo, o estilo retórico e literário clássico na Antiguidade tardia, fortemente ditado por Cícero, seguia um modelo rígido de composição em três níveis de organização do discurso. O primeiro, dito "estilo baixo", era recomendado ao ensino e à exegese, não devendo ser adornado, displicente ou incorreto. O segundo, "médio", recorria a figuras retóricas empregadas em contextos naturais à época, mais apropriado a elogios e repreensões ou à admoestação e à dissuasão. Por fim, o último, dito "sublime", suscitava os momentos de grande emoção, destinados especialmente a induzir os homens à ação. A mudança de paradigma na linguagem retórica e literária se dá fundamentalmente com Santo Agostinho, em cujos sermões emprega na forma estilística os níveis médio ou baixo - portanto de modo claro e 
didático - para tratar daquilo que é, em conteúdo, do mais alto teor sublime: a revelação cristã. Está posto o que se trata por sermo humilis:

[...] começa Santo Agostinho a explicar em que medida a doutrina da tripartição dos estilos pode ser utilizada na prática pelo orador cristão. [...] Os objetos baixos ou corriqueiros [...] perdem esse caráter quando introduzidos num contexto cristão, prestando-se então ao estilo sublime; e, inversamente, como mistérios da fé podem ser expostos nas palavras simples e acessíveis de estilo baixo. Isso representa um desvio tão marcante da tradição retórica e literária que chega quase a destruir seus fundamentos. (AUERBACH, 2012, p. 40-41)

Seguindo por essa linha de pensamento, a constituição histórico-filológica ajuda-nos a centralizar uma forma de concepção literária em Bandeira à luz dos termos do sermo humilis, em que o baixo - o cotidiano prosaico - revela tópicos mais sublimes, como no caso da maçã. Ainda seguindo em sua análise, Auerbach detém-se sobre a evolução linguística do termo "humilis", originariamente do latim clássico, à acepção mais comumente atribuída a "humilde" na modernidade. Ele recupera a raiz latina de humilis em humus, "solo", literalmente referindo-se ao baixo, mas que em sentido figurado empregava-se com o valor de reles, diminuto, insignificante. A literatura cristã, contudo, impregna o termo de novas acepções na figuração da linguagem, não mais necessariamente pejorativa, tais como modéstia, moderação, pia submissão e obediência, em consonância com tal tradição e concepção de mundo. Assim, embora humilis tenha-se tornado uma das denominações mais usuais para o estilo baixo, nas teorias cristãs, pelo dito "sermo humilis" agostiniano, o termo é o mais caro, uma vez que designa a própria encarnação: "na literatura cristã latina, exprime tanto o ambiente quanto o nível da vida e dos sofrimentos de Cristo [...]. Foi justamente por meio da irradiação de seus significados [...] que humilis alcançou posição tão dominante e tão sugestiva" (AUERBACH, 2012, p. 45). 
Isso posto, Auerbach nos apresenta a dialética fundamental que concebe a percepção de mundo cristã, em que humilis - o baixo, o terreno, o humano - se contrapõe a sublimis o alto, os céus, Deus. À luz de humilitas, portanto, desdobra-se uma noção social e espiritual dos destinatários a quem se dirige a doutrina cristã como exemplo de vida a ser seguido um modo de ser e estar no mundo humilde que, dialeticamente, carrega uma essência fundamentalmente sublime. Isomorficamente, essa concepção de mundo materializa-se no plano literário-discursivo em sermo humilis.

O "elemento de humilde cotidiano" na poesia de Bandeira opera de maneira semelhante tal modo de concepção de mundo e de elaboração poética: ocultando os mais elevados temas da condição humana em um discurso literário de falsa modéstia, "humilde" em tema e forma, revela-se, no alumbramento do próprio acontecer poético, sublime por excelência. Pelo prosaísmo de influências modernistas, pela incorporação temática do folclore e da banalidade cotidiana, pelo nivelamento de temas rasos e elevados, a obra amadurecida do poeta revela uma nova maneira de composição que difere das manifestações de cunho mais simbolista das obras anteriores. Passam a permear sua poesia os mais diversos elementos que evocam em imagem as memórias da infância no Recife, da juventude doente em Petrópolis, da vida adulta nas ruas de Santa Teresa e nos becos da Lapa - enfim, de seu cotidiano prosaico. A dimensão desse debate toma proporções ainda maiores em se tratando de sua produção em prosa, em especial no caso da crônica, em que o tempo histórico observado está intimamente ligado às condições do contexto de produção. 
Esse é um aspecto caro para que se possa prosseguir na fundamentação de uma concepção poética patrimonial na obra de Manuel Bandeira. Pensar a forma com que o poeta se dirige para os "escombros" de seu tempo (Cf. BENJAMIN, 2005, p. 87) vendo-Ihes dignificação para o que é patrimonializável nos mobiliza a compreender os sentidos postulados por Bandeira para conceituar "cotidiano" em interface com a dimensão da humildade. Uma vez que sua visão de mundo patrimonial se dá na esfera do humilde, ela não se volta para o monumental da História com $\mathrm{H}$ maiúsculo, mas para o detalhe, para o pequeno, o banal no cotidiano. Pelo humilde cotidiano, expresso estilisticamente também em forma prosaica e corriqueira, exprime o tempo presente que se manifesta ao seu redor em potente força realista, ao mesmo tempo em que o subverte em imagens poéticas do mais elevado tom sublime.

\section{POR UMA CONCEPÇÃO POÉTICA PATRIMONIAL EM MANUEL BANDEIRA}

Nesse ponto, aproximamo-nos da chave de leitura que nos permite elaborar uma concepção de mundo patrimonial na obra de Bandeira enquanto "fundação de uma poética" (ARRIGUCCI Jr., 2003). Independente de que patrimônio se fale, perpassa fundamentalmente sobre ele a noção de valor. O patrimônio é valorizado por seus mais diversos atributos, seja por fatores econômicos, seu contexto histórico e social ou da apreciação e julgamento ético e estético que dele se faz. Para Maria Cecília Londres Fonseca, "são esses processos de atribuição de valor que possibilitam uma melhor compreensão do modo como são progressivamente construídos os patrimônios" (FONSECA, 2005, p. 35), pois é do reconhecimento do valor atribuído que se coloca a vontade/necessidade de se projetar a manutenção do bem patrimonial para o futuro. A valoração do patrimônio, por sua vez, desdobra-se no sentido de salvaguarda. O bem cultural, enquanto patrimônio, prescinde de 
manutenção e preservação para seu entendimento no futuro como legado e herança potencial da memória e do passado.

Seguindo em nosso argumento, explorar o senso patrimonial do autor concebido em diálogo com suas experiências biográficas é também pensar em que medida o modo de ser se converte em modo de perceber patrimonialmente a vida e a poesia como forma de concepção do fazer poético. A visão de mundo patrimonial, assim, consiste em leitura subjetiva impregnada de juízo de valor previamente estabelecido e embasada em valores patrimoniais, ou seja, pautada nos sentidos de patrimônio e posse, preservação e destruição, perigo e valor, público e privado que, segundo Mário Chagas, "dão o contorno moderno à noção de patrimônio [...] [como] instrumento de mediação entre diferentes mundos, entre o passado, o presente e o futuro, entre o visível e o invisível" (CHAGAS, 2009, p. 40). Atribuindo valor patrimonial ao que é miúdo e aparentemente supérfluo, porém memorável pela dimensão afetiva e subjetiva que Ihe toca particularmente o corriqueiro e o banal no cotidiano, Bandeira institui seu humilde patrimônio.

Em Crônicas da província do Brasil, evidenciam-se três grandes blocos temáticos sobre os quais nossa pesquisa se detém para a análise das crônicas que compõem o volume na perspectiva patrimonial proposta. O primeiro diz respeito àquelas que evidenciam a salvaguarda e difusão do patrimônio de caráter material artístico e edificado. Nesse grupo, sobressai o interesse de Bandeira pelo Barroco colonial brasileiro, no qual vê a originalidade artística típica de nossa brasilidade em oposição à arte europeia neoclássica ou eclética em franco prestígio na virada do século XIX para o século XX. Na arquitetura, valoriza as cidades que preservam o conjunto arquitetônico colonial barroco, como na crônica "De Vila Rica de 
Albuquerque a Ouro Preto dos estudantes", "Bahia", "Recife", "Arquitetura brasileira", ou ainda em construções específicas, como o derrubado Solar de Megaípe, na crônica "Um purista do estilo colonial", ou das velhas igrejas coloniais de Olinda, Rio de Janeiro e Salvador, na crônica "Velhas igrejas". Nas manifestações artísticas de expressão barroca, a escultura de Aleijadinho é uma de suas maiores predileções, como salientado na crônica "O Aleijadinho". Sua visão de mundo patrimonial evidencia-se não apenas pelo enaltecimento do que é grandioso por sua concepção arquitetônica, mas principalmente pela presença de um ar provinciano e humilde que ainda reside nos "escombros da história" e em sua memória afetivo-saudosista:

Hoje ela [Ouro Preto] é a cidade dos estudantes. São eles que lhe dão vida e animação. Depois do jantar descem os rapazes das Lajes, onde as repúblicas alternam com os casebres das mulatinhas besuntadas de rouge e pó-de-arroz, e vêm cruzar as calçadas e encher os cafés tão simpáticos da rua de São José. Está claro que as mocinhas da cidade estão por ali também, passeando de braço dado. Naturalmente que se namora... Não há mais ouro, mas ainda Ihe resta à Imperial cidade essa outra coisa mais preciosa que o ouro - a mocidade, sorriso da velhice da Vila Rica de Nossa Senhora do Pilar. (BANDEIRA, 2006, p. 32)

O trecho explicita a força expressiva do traço de humildade que fundamenta essa concepção de mundo patrimonialmente. Resgatando o movimento temporal manifesto na crônica entre os dois momentos de Ouro Preto - a anteriormente gloriosa Vila Rica de Albuquerque em contraposição à decaída Ouro Preto dos estudantes de seu tempo Bandeira aponta-nos para o fato de que é na jovialidade vital dos estudantes, em contraste com a cidade decadente, que reside afetivamente seu humilde patrimônio. No trecho a seguir, a relação intrínseca entre a experiência afetiva do poeta e o desejo de salvaguardar o 
patrimônio histórico e artístico para além de seu valor patrimonial artístico-arquitetônico se mostra ainda mais evidente:

Este mês que acabo de passar no Recife me repôs inteiramente no amor da minha cidade. Há dois anos atrás, quando a revi depois de uma longa ausência, desconheci-a quase, tão mudada a encontrei. E sem discutir se essa mudança foi para melhor ou para pior, tive um choque, uma sensação desagradável, não sei que despeito ou mágoa. Queria encontrá-la como a deixei menino. Egoisticamente, queria a mesma cidade da minha infância.

Por isso diante do novo Recife, das suas avenidas orgulhosamente modernas, sem nenhum sabor provinciano, não pude reprimir o mau humor que me causava o desaparecimento do outro Recife, o Recife velho, com a inesquecível Lingueta, o Corpo Santo, o Arco da Conceição, os becos coloniais... (BANDEIRA, 2006, p. 109)

As crônicas "De Vila Rica de Albuquerque a Ouro Preto dos estudantes", "Recife" e "A festa de N. Sra. da Glória do Oiteiro" revelam ainda que a memória do poeta preserva o monumento à ótica da ideia de autenticidade e da perda da "aura" da obra de arte explorada por Walter Benjamin (2012) quando trata da questão da reprodutibilidade técnica. Assim, nas críticas em que Bandeira faz ao "desastrado entendimento" das "restaurações depredadoras" do casario de Ouro Preto na tentativa de retomada do que entende por "alguma cousa de nosso" (Cf. BANDEIRA, 2006, p. 15-16) - isto é, a dita brasilidade -, nota-se o desejo de preservar "o aqui e agora da obra de arte, sua existência única, no lugar em que ela se encontra" (BENJAMIN, 2012, p. 181). Sua visão de mundo patrimonial fica nitidamente expressa pelo desejo de manter intacta sua memória afetiva com relação ao Recife velho e a propósito da imagem cristalizada que tinha da igrejinha de Nossa Senhora da Glória do Outeiro tal como a viu pela última vez:

Tive este ano particular interesse em visitar a ermida porque sabia que a irmandade levara a efeito grandes obras internas de restauração. Entrei o pórtico receoso, embora 
tivesse lido nos jornais uma entrevista em que um dos membros daquela irmandade assegurava o respeito que presidira aos trabalhos de restauração. 0 meu receio infelizmente se confirmou. A pequenina nave, despojada dos seus ouros e das suas argamassas patinadas, perdeu o encanto que lhe vinha da idade. Tudo está novo ou renovado. Baixei os olhos e saí depressa para guardar nos olhos a imagem das velhas capelinhas e tribunas, como eu as vi até o ano passado. (BANDEIRA, 2006, p. 81-82)

A mesma sensação de apreço pelo que entende ser "autêntico" no patrimônio edificado, que preserva a sua "aura" justamente por demarcar a presença dos "escombros" da história a que Benjamin se refere, aparece registrada na crônica "Velhas igrejas", ao mencionar os "ouros amortecidos de pátina":

Tremo sempre que leio nos jornais a notícia de que alguma das nossas igrejas vai sofrer reparações. Se as obras se limitassem a uma simples consolidação e limpeza, à restauração no estilo geral de detalhes que trabalhos anteriores já desfiguraram, se deixassem como estão os seus ouros amortecidos de pátina, não haveria decerto inconveniente. Mas desgraçadamente sabemos todos como essas coisas se fazem. (BANDEIRA, 2006, p. 71)

O segundo bloco temático que chama nossa atenção no volume é a valorização do patrimônio de caráter imaterial. Nesse campo, Bandeira é original: tal importância só foi reconhecida em cenário internacional nos anos 2000, com a publicação da Convenção para a salvaguarda do patrimônio cultural imaterial em outubro de 2003, em Paris. Nesse sentido, chamam atenção as crônicas "Fala brasileira", "A festa de N. S. da Glória do Oiteiro", "O enterro de sinhô", "Sambistas", "Poesia do sertão" e "Candomblé", em que manifesta seu senso preservacionista por música, arte popular e folclore brasileiro. Como no primeiro caso, a concepção patrimonial de Bandeira se revela pelo enaltecimento do pitoresco provincianismo carregado de humildade: 
[...] Onde o brasileiro mais sente nos olhos o gosto do Brasil é decerto quando fica parado num pátio de igreja em dia de festa de Nossa Senhora. [...]

Esse prazer, que ainda subsiste forte no ambiente mais tradicional das províncias, quase desapareceu na capital do país. São sempre as mesmas as festas de igrejas, mas sem aquele pitoresco popular que desenvolvia no adro o movimento ruidoso das romarias.

Hoje no Rio só há duas solenidades religiosas a sustentar a tradição da cidade: a festa da Penha e a festa da Glória. (BANDEIRA, 2006, p. 79)

Já na crônica "Sambistas", Bandeira demonstra preocupação com o registro e a salvaguarda da música popular brasileira como expressão e manifestação de natureza imaterial. Nela, o cronista trata da descoberta de um samba que lhe agrada, mas cuja autoria é desconhecida, atribuída a um sambista de baixa popularidade à época, seu Candu. Entre as suas reflexões, o cronista reclama da dificuldade de registro das autorias das canções, e de como muitas das músicas, não gravadas em disco, perdiam-se no tempo e espaço. Para além disso, deixa implícita sua crítica ao fenômeno da indústria cultural de que trata Adorno e Horkheimer (1985) vivido no período do Estado Novo com a exaltação do samba a símbolo identitário da cultura nacional, o que levou ao fenômeno da apropriação cultural e consequente exploração mercadológica pela indústria fonográfica das expressões de caráter popular que apagavam a originalidade e autoria das canções.

[...] Isso tudo me fez refletir como é difícil apurar afinal de contas a autoria desses sambas cariocas que brotam não se sabe donde. Muitas vezes a gente está certo que vem de um Sinhô, que é majestade, mas a verdade é que o autor é seu Candu, que ninguém conhece.

E afinal quem sabe lá se é mesmo seu Candu? Possivelmente atrás de seu Candu estará o que não deixou vestígio de nome no samba que toda a cidade vai cantar. (BANDEIRA, 2006, p. 155) 
Chegando ao último bloco, há um senso preservacionista na difusão do patrimônio literário e artístico de seu tempo histórico. Em Crônicas da província do Brasil, Bandeira dedica uma série de textos aos seus contemporâneos. Na literatura, são os casos de "Graça Aranha", "Carlos Drummond de Andrade", "Augusto Frederico Schmidt", "Guilherme de Almeida", "Raul de Leoni", "Mário de Andrade". No campo das Artes Visuais, ressaltam-se as crônicas "Portinari" e "Tarsila Antropófaga". Em muitos desses artistas, destaca a expressividade poética que perpassa também pela concepção provinciana e humilde em suas obras, a exemplo de Portinari: "Creio poder discernir em Portinari esse espírito do interior brasileiro - tímido, acanhado, mas observador, e, com todo o seu medo de ser debicado, debicador de primeira" (BANDEIRA, 2006, p. 193). Ou também em Drummond: “[...] o primeiro poeta tipicamente mineiro [...]. Os mineiros são, mais que os outros nossos patrícios, dotados daquelas qualidades de reflexão tarda, de atitude à parte, de desconfiança do entusiasmo, de gosto das segundas intenções [...]" (BANDEIRA, 2006, p. 124). Destaque-se "Velórios", que praticamente encerra o bloco das 42 crônicas de temática nacional: dedica-se a resenhar o livro homônimo, único de ficção redigido por Rodrigo Melo Franco de Andrade - o qual se faz, assim, presente no início, com a dedicatória, e ao fim do volume, com a resenha, demarcando a força patrimonial que se manifesta no decorrer de todo o seu livro de crônicas.

\section{CONSIDERAÇÕES FINAIS}

Em 2018, comemoram-se o cinquetenário de morte de Manuel Bandeira e os oitenta anos de criação do IPHAN. A presente pesquisa, ainda em curso, vem propor ponto de articulação importante no entrecruzamento de ambas as histórias. Enfocando na produção em prosa do poeta, especificamente sobre suas crônicas, almejamos com nossa perspectiva 
de análise, pela ótica patrimonial, enriquecer a fortuna crítica de um dos maiores poetas de Língua Portuguesa.

Seguindo uma tradição crítica em ler o traço da humildade como uma chave de leitura na obra de Bandeira, esse trabalho esboçou, ainda que de modo incipiente, uma concepção poética na articulação entre patrimônio e humildade, revelando uma perspectiva ainda original para a temática patrimonial que não se centra na lógica do "monumental". É o aspecto da humildade que lhe permite desse modo atentar para as sutilezas sublimes de seu entorno que ocultam o poético em sua visão de mundo.

Atento à tríade patrimonial (material, imaterial e literária), Bandeira nos revela a sofisticação de sua visão de mundo: revisita a originalidade nas obras de arte de nosso passado colonial em busca da dita "brasilidade" e a atualiza na produção artística do seu tempo presente, especialmente de natureza modernista. Além disso, não perde de vista que as expressões e manifestações do próprio fazer, de caráter imaterial, reverberam ainda na atualidade muitas das práticas espontâneas de nosso passado colonial. Havendo muito ainda a explorar, seguimos no projeto de revelar os alumbramentos poéticos revestidos de uma prosa pretensamente "humilde", na qual reside justamente sua maior vivacidade.

\section{REFERÊNCIAS}

ADORNO, Theodor; HORKHEIMER, Max. "A indústria cultural: o esclarecimento como mistificação das massas". In: . Dialética do esclarecimento. Rio de Janeiro: Zahar, 1985.

ARRIGUCCI Jr., Davi. Enigma e comentário: ensaios sobre literatura e experiência. São Paulo: Companhia das Letras, 1986. 
Humildade, paixão e morte: a poesia de Manuel Bandeira. São Paulo: Companhia das Letras, 2003.

AUERBACH, Erich. Ensaios de literatura ocidental. São Paulo: Editora 34; Editora Duas Cidades, 2012.

BANDEIRA, Manuel. Crônicas da província do Brasil. 2. ed. São Paulo: Cosac Naify, 2006 (1937).

Estrela da vida inteira. 20. ed. Rio de Janeiro: Nova Fronteira, 1993 (1966).

Itinerário de Pasárgada. 7. ed. Rio de Janeiro: Global, 2012 (1954).

BENJAMIN, Walter. "A obra de arte na era da reprodutibilidade técnica". In: . Magia e técnica, arte e política: ensaios sobre literatura e história da cultura. São Paulo: Brasiliense, 2012.

"Sobre o conceito de história". In: LÖWY, Michel. Aviso de incêndio: uma leitura das teses "Sobre o conceito de história". São Paulo: Boitempo Editorial, 2005.

CHAGAS, Mário. A imaginação museal: museu, memória e poder em Gustavo Barroso, Gilberto Freyre e Darcy Ribeiro. Rio de Janeiro: IBRAM; Garamond, 2009.

FONSECA, Maria Cecília Londres. O patrimônio em processo: trajetória da política federal de preservação no Brasil. Rio de Janeiro: Editora UFRJ, 2005.

GUIMARÃES, Júlio Castañon. "Posfácio". In: BANDEIRA, Manuel. Crônicas da província do Brasil. 2. ed. São Paulo: Cosac Naify, 2006.

Artigo recebido em: 31 de maio de 2018. Artigo aprovado em: 04 de agosto de 2018. 